\title{
Method using ortho-tolidine for the quantitative determination of haemoglobin in serum and urine
}

\author{
G. PARKER LEWIS ${ }^{1}$ \\ From the Southern General Hospital, Glasgow
}

SYNOPSIS Following a study of the spectrophotometric properties of ortho-tolidine and its oxidation products, with particular attention to variation brought about by change in the hydrogen ion concentration, a method for the quantitative estimation of haemoglobin in serum and urine in which ortho-tolidine is substituted for benzidine in a peroxidase system is described. The method is designed to measure haemoglobin value within the range 0-125 mg. per $100 \mathrm{ml}$. Evidence is presented showing that it gives results equal in accuracy and reproducibility to a benzidine method in common use and for reasons stated is a more satisfactory technique for estimating the haemoglobin content of urine.

Since the demonstration of a high incidence of carcinoma of the bladder amongst industrial workers who inadvertently ingest or inhale benzidine in small quantities over long periods (Scott, 1952; Barsotti and Vigliani, 1952; Baker, 1953; Douillet, 1956), the use of this substance in biochemical laboratories and clinical side rooms has been strongly discouraged.

As a consequence, during the past few years, the chemical ortho-tolidine has been substituted for benzidine ${ }^{2}$ in tests designed to demonstrate qualitatively the presence of haemoglobin in faeces and urine. In spite of the similarity in chemical structure to benzidine, ortho-tolidine has not to date been reported as causing carcinoma in man. Its substitution for benzidine as a means of determining quantitatively the level of haemoglobin in serum and urine in some pathological states seems desirable.

\section{THE ORTHO-TOLIDINE PEROXIDASE REACTION}

CHEMICAL STRUCTURE OF ORTHO-TOLIDINE Orthotolidine (4,4'-diamino-3,3'-dimethyl-biphenyl) has the empirical formula $\mathrm{NH}_{2} \mathrm{CH}_{3} \mathrm{C}_{6} \mathrm{H}_{3} \mathrm{C}_{6} \mathrm{H}_{3} \mathrm{CH}_{3} \mathrm{NH}_{2}$. It is a colourless crystalline substance with a melting point of $126.5^{\circ} \mathrm{C}$. It is slightly soluble in ethyl alcohol. It is prepared from o-nitro-toluene by reduction to the corresponding hydrazo compound by rearrangement in the same manner as benzidine is prepared from nitrobenzene (Vobes, 1959).

'Present address: University Medical Unit, Stobhill General Hospital. Glasgow. N.1.

'Hematest and Occultest, Ames Company, London.

Received for publication 27 July 1964.

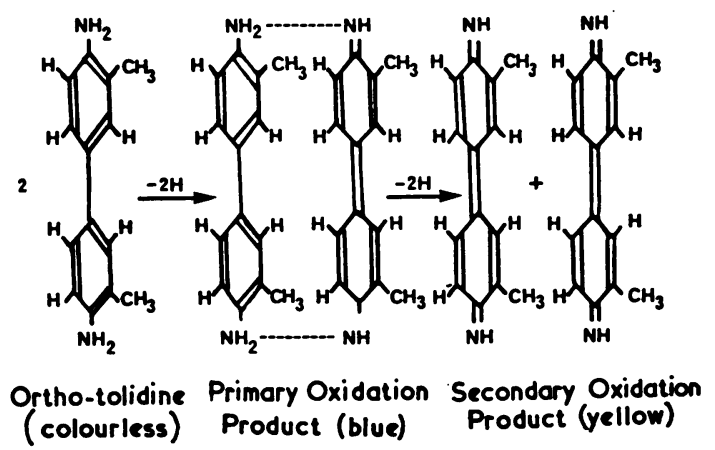

FIG. 1. Ortho-tolidine and its oxidation products.

The structural changes occurring on oxidation are represented by the formulae shown in Figure 1.

MATERIALS AND METHODS

All the spectrophotometric studies of the ortho-tolidine peroxidase reaction described below were carried out using a standard procedure.

REAGENTS All reagents were of 'Analar' or equivalent grade.

1 Ortho-tolidine-acetic acid reagent (see Appendix)

2 Hydrogen peroxide solution (see Appendix)

3 Haemoglobin standard solution (see Appendix)

4 Final diluents

$10 \%$ Acetic acid (see Appendix)

Acetate buffer $p \mathrm{H} \mathrm{4.63}$

Citrate buffer $p \mathrm{H} \mathrm{4.69}\}$ (King and Wootton, 1956) 
APPARATUS All readings were made using a Unicam S.P. 600 spectrophotometer.

PROCEDURE Of the haemoglobin standard, $0.02 \mathrm{ml}$. was washed into $1 \mathrm{ml}$. of the ortho-tolidine-acetic acid reagent. After thorough mixing, $1 \mathrm{ml}$. of the hydrogen peroxide solution was added and mixed by swirling. The reaction was allowed to proceed for 10 minutes (see 'Timing of the ortho-tolidine reaction' below), at the end of which $10 \mathrm{ml}$. of the selected buffer diluent was added. The test solution was then immediately read in the spectrophotometer.

\section{RESULTS}

SPECTROPHOTOMETRIC PROPERTIES Like benzidine, ortho-tolidine has two oxidation products. The primary oxidation product is blue, having a maximum absorption peak at $630 \mathrm{~m} \mu$. The secondary oxidation product is yellow and has a maximum absorption at $435 \mathrm{~m} \mu$ (Fig. 2).

Table I gives a summary of the spectrophotometric properties of ortho-tolidine compared with those of benzidine.

EFFECT OF $p \mathrm{H} \quad \mathrm{A}, \mathrm{B}$, and $\mathrm{C}$ (Fig. 3) are the spectrophotometric absorption curves derived from three ortho-tolidine peroxidase reactions in which the quantities of a standard haemoglobin solution,

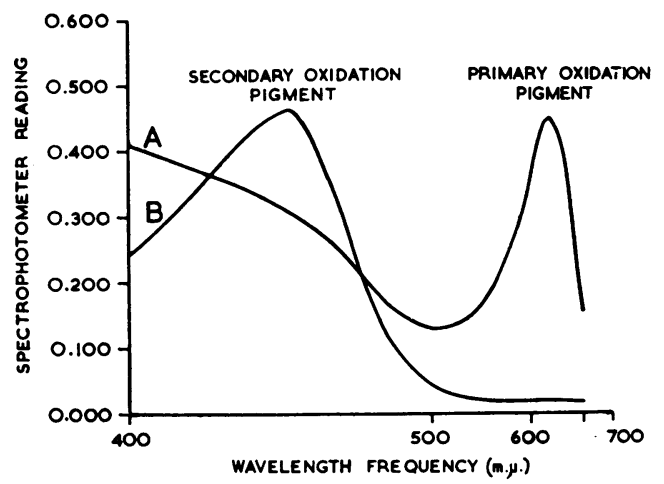

FIG. 2. A Ortho-tolidine peroxidase reaction with water as final diluent (final $\mathrm{pH} 4 \cdot 6$ ).

$B$ Ortho-tolidine peroxidase reaction with glacial acetic acid as final diluent (final $\mathrm{pH} 1 \cdot 50$ ). ortho-tolidine-acetic acid reagent and hydrogen peroxide were the same, but the final $p \mathrm{H}$ of the test solutions for reading in the spectrophotometer were made $3 \cdot 75,2 \cdot 94$, and $2 \cdot 20$ respectively by using three different diluting agents. It can be seen that a high $p \mathrm{H}$ favours the formation of the primary oxidation product whereas a low final $p \mathrm{H}$ favours the secondary oxidation product.

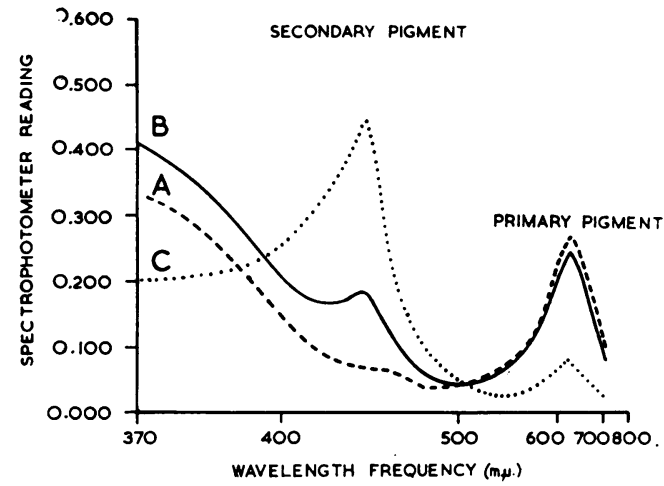

FIG.3. Effect of $\mathrm{pH}$ on the oxidation products of orthotolidine.

A Final $\mathrm{pH} 3.75$ (citrate buffer $\mathrm{pH} 4.96$ used as diluent).

$B$ Final $\mathrm{pH} 2.94$ (acetate buffer $\mathrm{pH} 4.63$ used as diluent).

C Final $\mathrm{pH} 2 \cdot 20(10 \%$ acetic acid used as final diluent $)$.

Compared with benzidine, the primary oxidation product of ortho-tolidine is relatively stable, depending upon the $p \mathrm{H}$ of the medium in which it exists. The conversion of the primary to the secondary pigment is inhibited by raising the $p \mathrm{H}$ of the solution. This factor is of limited practical application because at high $p \mathrm{H}$ the primary oxidation product is rapidly reduced to a leuco derivative. This last change appears to be irreversible as far as re-oxidation by addition of more peroxidase (haemoglobin) is concerned. Lowering the $p \mathrm{H}$ favours the conversion of the primary pigment to the secondary form. This pigment when formed is quite stable but can be rendered colourless by the action of strong reducing agents such as ascorbic acid. This change is also irreversible.

Figure $4 \mathrm{~A}$ shows the stability of the primary

TABLE I

COMPARISON OF SPECTROPHOTOMETRIC CHARACTERISTICS OF OXIDATION PRODUCTS OF BENZIDINE AND ORTHO-TOLIDINE

\begin{tabular}{|c|c|c|c|c|}
\hline & \multicolumn{2}{|l|}{ Benzidine } & \multicolumn{2}{|l|}{ Ortho-tolidine } \\
\hline & Primary Pigment & Secondary Pigment & Primary Pigment & Secondary Pigment \\
\hline $\begin{array}{l}\text { Colour } \\
\text { Extinction maximum } \\
\text { Stability at } p H \quad 2 \cdot 20 \\
\text { Stability at } p H \mathbf{3} \cdot \mathbf{7 5}\end{array}$ & $\begin{array}{l}\text { Blue } \\
600 \mathrm{~m} \mu . \\
\text { Very unstable } \\
\end{array}$ & $\begin{array}{l}\text { Red } \\
515 \mathrm{~m} \mu \\
\text { Stable } \\
-\end{array}$ & $\begin{array}{l}\text { Blue } \\
630 \mathrm{~m} \mu . \\
\text { Stable } \\
\text { Moderately stable }\end{array}$ & $\begin{array}{l}\text { Yellow } \\
435 \mathrm{~m} \mu \\
\text { Stable }\end{array}$ \\
\hline
\end{tabular}




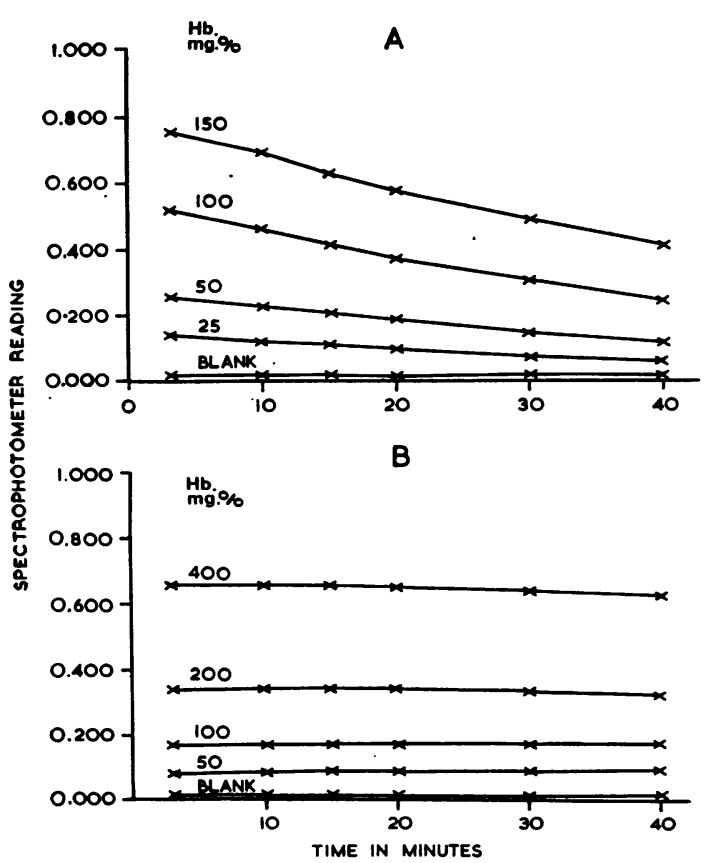

FIG. 4. Stability of the primary oxidation product of ortho-tolidine.

A Using citrate buffer ( $\mathrm{pH} 4.96)$ as diluent (final $\mathrm{pH} 3.75)$.

B Using $10 \%$ acetic acid as diluent (final $\mathrm{pH} 2 \cdot 20$ ).

The primary oxidation product of ortho-tolidine is stable at $\mathrm{pH} 2 \cdot 20$, although the intensity of colour development is appreciably less than when the citrate buffer, giving a final $\mathrm{pH}$ of $3 \cdot 75$, is used.

oxidation product of ortho-tolidine at varying concentration when made up with a citrate buffer diluent ( $p \mathrm{H} \mathrm{5.0)} \mathrm{giving} \mathrm{a} \mathrm{final} p \mathrm{H}$ of 3.75. It can be seen that when this diluent is used a rapid fall-off in the colour intensity occurs. Spectrophotometric readings must, therefore, be made immediately following dilution if an accurate assessment of the maximum intensity of the reaction is to be obtained.
Figure 4B shows the results of similar experiments in which $10 \%$ acetic acid was used as the diluent making the $p \mathrm{H}$ of the final solution $2 \cdot 20$. The intensity of colour due to the primary pigment is less than when the citrate buffer diluent is used but the fall-off in pigment intensity is far less rapid, showing that at this $p \mathrm{H}$ the primary pigment is more stable.

In both the above instances the intensity of primary pigment colour was directly proportional to the concentration of peroxidase taking part in the reaction, Beer's law being obeyed to an extinction coefficient of at least $0 \cdot 700$ (Fig. 5).

TIMING OF THE ORTHO-TOLIDINE REACTION In order to determine the optimum time for the addition of the acetic acid diluent following the start of the

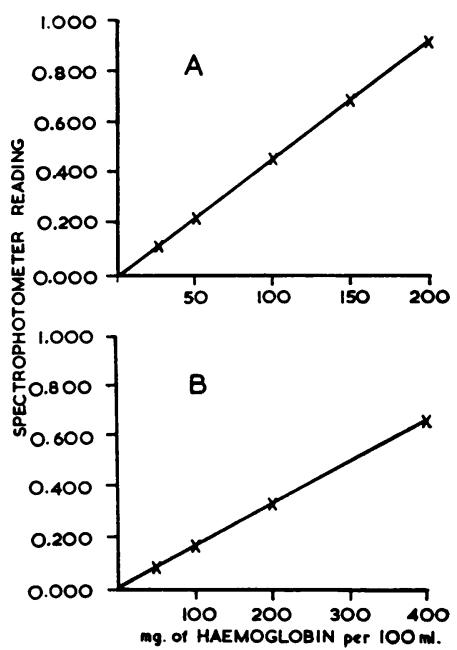

FIG. 5. The graphs show how the intensity of colour develcpment in an ortho-tolidine peroxidase reaction read at 10 minutes following dilution is directly dependent upon the quantity of haemoglobin participating. Beer's law is obeyed to an extinction coefficient of at least 0.700.

$A$ Final $\mathrm{pH} 3.75$ (citrate buffer diluent).

B Final $\mathrm{pH} 2 \cdot 20(10 \%$ acetic acid diluent $)$.

TABLE II

TIMING THE ORTHO-TOLIDINE PEROXIDASE REACTION ${ }^{1}$

Reaction Time (minutes $\bar{p} \mathrm{H}_{2} \mathrm{O}_{2}$ )

\begin{tabular}{|c|c|c|c|c|c|c|c|c|c|c|c|}
\hline & 5 & 10 & 15 & 20 & 25 & 30 & 40 & 45 & 55 & 60 & 65 \\
\hline $\begin{array}{l}1 \\
2 \\
3 \\
4 \\
5 \\
6 \\
7 \\
8\end{array}$ & 0.489 & $\begin{array}{c}0.520 \\
0.538\end{array}$ & $\begin{array}{c}0.527 \\
0.554 \\
0.565 \\
\end{array}$ & $\begin{array}{c}0.528 \\
0.550 \\
0.560 \\
0.583 \\
\end{array}$ & $\begin{array}{l}0.535 \\
0.552 \\
0.550 \\
0.581 \\
0.585 \\
\end{array}$ & $\begin{array}{l}0.527 \\
0.530 \\
0.537 \\
0.569 \\
0.556 \\
0.573 \\
\end{array}$ & $\begin{array}{l}0.518 \\
0.525 \\
0.521 \\
0.543 \\
0.532 \\
0.560 \\
0.570 \\
\end{array}$ & $\begin{array}{l}0.505 \\
0.510 \\
0.503 \\
0.523 \\
0.517 \\
0.553 \\
0.562\end{array}$ & $\begin{array}{l}0.478 \\
0.485 \\
0.481 \\
0.505 \\
0.493 \\
- \\
-\end{array}$ & $\begin{array}{l}0.459 \\
0.481 \\
0.463 \\
0.483 \\
0.477 \\
0.508 \\
0.508 \\
0.492 \\
\end{array}$ & $\begin{array}{l}- \\
- \\
- \\
- \\
\overline{0.478}\end{array}$ \\
\hline
\end{tabular}

The table shows how maximum colour development occurs 20 to 25 minutes following the start of the peroxidase reaction (reactions 4 and 5 ), but that the greatest stability of colour in the final test solution is obtained by allowing the reaction to proceed for only 10 to 15 minutes before diluting with $10 \%$ acetic acid and reading in the spectrophotometer (reactions 2 and 3 ). 
ortho-tolidine peroxidase reaction, eight identical reactions were studied (Table II) but the time interval between the addition of the hydrogen peroxide solution and final dilution with $10 \%$ acetic acid was varied. All the initial spectrophotometric readings were made immediately following dilution of the reaction with acetic acid.

It will be seen that maximum colour intensity develops when the reaction is allowed to stand for 20 to 25 minutes before dilution (boxed numbers). Following dilution, a fall-off in colour intensity occurs (unboxed numbers).

Maximum stability is observed when the reaction is diluted 10-15 minutes after standing. The optimum time interval between the start of the reaction (following addition of hydrogen peroxide) and dilution is 10 minutes.

In the appendix to this paper is given a detailed description of a quantitative method for estimating the haemoglobin content of serum and urine using ortho-tolidine as the hydrogen donator in a peroxidase system. This method was evolved using the above information concerning the spectrophotometric properties of ortho-tolidine. Although technically similar to the benzidine method described by Crosby and Furth (1956), it differs in that first, the reaction is allowed to proceed for 10 instead of 20 minutes, and, secondly, spectrophotometric measurement of the intensity of the primary oxidation product of ortho-tolidine is made at a wavelength frequency of 630 millimicrons instead of at 515 millimicrons as used for measuring the intensity of the secondary oxidation product of benzidine.

COMPARISON OF BENZIDINE AND ORTHO-TOLIDINE METHODS FOR QUANTITATIVE ESTIMATION OF HAEMOGLOBIN IN SERUM Figure 6 compares the results of haemoglobin estimation using both the benzidine method (Crosby and Furth, 1956) and the orthotolidine technique described in detail in the appendix. The 160 sera examined were obtained from patients subjected to experimentally induced haemoglobinaemia.

The benzidine method results are arranged in ascending order of magnitude on the left hand side of the serum haemoglobin axis, whilst the respective values obtained using the ortho-tolidine technique are arranged on the right.

It will be seen that the ortho-tolidine method results are within $\pm 5 \mathrm{mg}$. of haemoglobin per $100 \mathrm{ml}$. of the values obtained using the benzidine method.

ESTIMATION OF HAEMOGLOBIN IN URINE Crosby and Furth (1956) point out that when their method is used to measure the haemoglobin content of urine

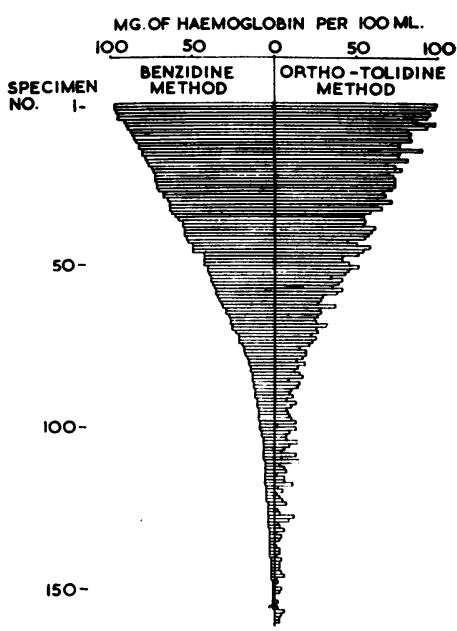

FIG. 6. Comparison of the benzidine and ortho-tolidine methods for the quantitative estimation of haemoglobin in serum. One hundred and sixty sera were studied. Results using the benzidine method are shown on the left hand side of the serum haemoglobin axis whilst the results obtained using the ortho-tolidine method are shown on the right.

samples, sulphates and urates normally present form insoluble complexes with benzidine and can cause it to 'salt out' of solution. This reduces the concentration of benzidine available for participation in the peroxidase reaction and also causes turbidity of the final test solution. To overcome this, they recommend overnight dialysis of the urine against normal saline so that the undesirable salts are removed. Following such a procedure, a correction factor needs to be applied for gain or loss of urine volume due to dialysis.

Ortho-tolidine has two advantages over benzidine when being considered for use for the estimation of the haemoglobin content of urine. First, it is more soluble than benzidine in $90 \%$ acetic acid and, secondly, weight for weight it gives a greater intensity of colour, thus allowing the strength of the reagent to be appreciably reduced. Both these factors decrease the ability of urinary sulphates and urates to 'salt out' ortho-tolidine. In fact, providing the concentration of the ortho-tolidine reagent is kept below $0.25 \mathrm{~g} . \%$ and the quantity of urine used less than $0.02 \mathrm{ml}$, the method as described in the appendix can be applied without modification, and without the necessity of pre-estimation dialysis. When small levels of haemoglobin are to be measured enhancement of the ortho-tolidine colour development can be achieved by using the citrate buffer instead of $10 \%$ acetic acid, but measurement of colour intensity requires to be made immediately following dilution of the peroxidase reaction. 
I thank Dr. Laurance D. W. Scott for his constant encouragement during the prosecution of this work; Dr. J. Wilson Chambers for helpful advice during the preparation of this paper; and Dr. Janet Browning and Dr. Margaret Fletcher for invaluable constructive criticism during many discussions.

\section{APPENDIX}

\section{A METHOD FOR THE DETERMINATION OF SERUM HAEMOGLOBIN USING ORTHO-TOLIDINE}

REAGENTS Glassware for storage of reagents must be cleaned with dilute $\mathrm{HCl}$ and washed with deionized water.

1 Ortho-tolidine reagent Ortho-tolidine (Analar), $0.25 \mathrm{~g}$., is dissolved in $80 \mathrm{ml}$. of glacial acetic acid and $10 \mathrm{ml}$. of water added. After mixing, the volume is made up to $100 \mathrm{ml}$. with glacial acetic acid. The reagent tends to darken on keeping but this can be reduced to a minimum by storing in a refrigerator at $5^{\circ} \mathrm{C}$. This reagent should be prepared freshly every eight to 12 weeks.

2 Hydrogen peroxide Two ml. of a $60 \mathrm{vol} . \%$ solution of hydrogen peroxide is made up to $100 \mathrm{ml}$. with distilled water. This reagent is prepared freshly every six to 10 days and is stored in a refrigerator when not in use.

3 Standard haemoglobin solution A fresh sample of $20 \mathrm{ml}$. of venous blood is mixed with $5 \mathrm{ml}$. of a $3 \%$ solution of sodium citrate. The red cells are separated from the plasma by centrifuging and the supernatant plasma removed with a Pasteur pipette. Then $0.9 \%$ saline is added to restore the volume to $20 \mathrm{ml}$. After mixing, the suspension of red cells is placed in a deep freeze refrigerator $\left(-15^{\circ} \mathrm{C}\right.$.) for 12 hours so that haemolysis of the red cells is effected.

After melting, red cell debris is separated by centrifuging for one hour at a speed of 12,000 r.p.m. (M.S.E. high speed refrigerated centrifuge). The clear winecoloured supernatant is then drawn off with a Pasteur pipette. This solution is then completely cleared of all remaining debris by passing through a Seitz filter. The precise haemoglobin content of this solution is then determined using the alkaline haematin method (Varley, 1962). By suitable dilution a $200 \mathrm{mg}$. haemoglobin standard is prepared from this stock solution; $0.5 \mathrm{ml}$. of this when mixed with $0.5 \mathrm{ml}$. haemoglobin-free serum or urine makes a haemoglobin standard of $100 \mathrm{mg}$. per $100 \mathrm{ml}$.

4 Acetic acid diluent Glacial acetic acid, $100 \mathrm{ml}$., is diluted to 1 litre with deionized water.
APPARATUS All glassware should be acid cleaned.

1 Spectrophotometer set at the wavelength $630 \mathrm{~m} \mu$.

2 Glass cuvettes with $10 \mathrm{~mm}$. light path $\times 3$.

3 Interval timer with ten minute sweep.

4 Test tubes of $15 \mathrm{ml}$. capacity.

5 Sahli pipettes $0.02 \mathrm{ml}$. grade A, N.P.L. (one for each unknown plus one for the haemoglobin standard), $2 \times 5 \mathrm{ml}$. graduated pipettes, $1 \times 10 \mathrm{ml}$. graduated pipette or a $10 \mathrm{ml}$. automatic delivery pipette.

PROCEDURE For each unknown, $1 \mathrm{ml}$. of the orthotolidine reagent is placed in a test tube. Two other tubes are prepared in a similar manner, one for the haemoglobin standard and the second for the reagent blank and $0.02 \mathrm{ml}$. of the unknown is washed into the first tube. A similar quantity of the haemoglobin standard is washed into the second. The tubes are mixed by swirling. After the lapse of two minutes, $1 \mathrm{ml}$. of the hydrogen peroxide reagent is added to each tube. The contents are again mixed by swirling. They are then left to stand for precisely 10 minutes, using an interval timer. Then $10 \mathrm{ml}$. of the acetic acid diluting agent is added to each tube and after mixing by upending, the solutions are transferred to cuvettes and immediately read in the spectrophotometer. The reagent blank (ortho-tolidine, hydrogen peroxide plus acetic acid diluent) is used for adjusting the spectrophotometer to zero.

The optical density of the standard represents a haemoglobin concentration of $100 \mathrm{mg} . \%$. The optical density of the unknown measures the concentration of haemoglobin in the sample serum under test.

The above procedure has been designed for measuring serum haemoglobin concentration within the range 0-125 mg. \%. The method can be made more sensitive by: 1 Decreasing the volume of diluent added before reading in the spectrophotometer; 2 increasing the concentration of ortho-tolidine in the ortho-tolidine reagent; 3 increasing the quantity of serum used during the test to $0.04 \mathrm{ml}$; 4 raising the $p \mathrm{H}$ of the final test solution by using the citrate buffer instead of the $10 \%$ acetic acid diluent but, when this is done, reading of the colour intensity in the spectrophotometer must be made immediately after dilution.

\section{REFERENCES}

Baker, R. K. (1953). Cancer Res., 13, 137.

Barsotti, M., and Vigliani, E. C. (1952). Arch. industr. Hyg., 5, 234. Crosby, W. H., and Furth, F. W. (1956). Blood, 11, 380.

Douillet, M. (1956). J. Urol. méd. chir., 62, 795.

King, E. J., and Wootton, I. D. P. (1956). Micro-Analysis in Medical Biochemistry, 3rd ed., p. 271. Churchill, London.

Scott, T. S. (1952). Brit. J. industr. Med., 9, 127.

Varley, H. (1962). Practical Clinical Biochemistry, 3rd ed., p. 494. Heinemann, London.

Vobes, D. H. (1959). Personal communication. 